\title{
WAYS OF MAINTAINING THE QUALITY OF FINANCIAL AUDIT IN THE CONTEXT OF VALIDATING FINANCIAL STATEMENTS
}

https://doi.org/10.47743/jopafl-2021-20-10

\author{
Vlad BULAU \\ Alexandru Ioan Cuza University \\ Iasi Romania \\ vladotb@yahoo.com
}

\begin{abstract}
It is well known that an economic and social entity, which keeps an accounting record in accordance with the provisions of the International Accounting Standards, carries out a credible and correct activity. The aim of the regular check of the activity of an enterprise by a professional in the field, who has adequate professional and moral qualities is that of generating trust in the accounting information provided by the entity. The importance of financial audit lies in the confirmation and increase of the credibility of the information found in the financial statements, indispensable for the future decisions of their users. The fact that the information was obtained and presented in accordance with generally accepted accounting standards and principles makes it more plausible.
\end{abstract}

Keywords: accounting, financial audit, quality, accurate image, financial statements

\section{Introduction}

In today's world, of globalized capitalism, the pace of change has shifted to the production of information and knowledge. Accounting has aligned itself with the new requirements through its product, the accounting information, by trying to suggest some solutions and strategies that economic actors need to follow. During our research, we noticed that changes in accounting standards, norms and regulations have had an effect on the entire set of users, leading to gains or losses for each party involved. The field of accounting is undoubtedly one of the most strictly regulated activities. However, the complexity and diversity of practical cases that may arise make it impossible for these regulations to cover any scenario. This leaves room for professional reasoning and allows it to intervene where the rule fails to distinguish. Thus, based on the experience gained over time, the accountant must record transactions and events, taking into account both his/her own judgment and the general principles of accounting.

Professor Ion Ionașcu believes that "Science begins with speculation, that is, with philosophy, and flows into philosophy as well, the adventure of knowledge being endless" (Ionașcu, 1997). Accounting is a science of order and balance in economics and it has followed the path from philosophy to concreteness, but without reaching a final or ultimate form. The dynamics of the science of accounts is demonstrated both by the continuous scientific activity around it and by the normative instrument that is in a permanent change and evolution. Even if the tendency of normalization of the profession is obvious, the conventions depend to a large extent on the national specificity. Despite all the differences between financial reporting systems, users appreciate the rigor of accounting information, 
with all its inherent limitations. We know that there is no absolute truth, but only a sum of relative truths.

\section{The role of accounting and auditing in ensuring the quality of financial information}

The importance of accounting is underlined by its definition as a formalized language of communication in the business world. The phenomenon of capital migration from more developed to developing countries, including the expansion of transnational companies in a globalized environment has accelerated the normalization of accounting standards and rules. The rules governing accounting and financial reporting are based on the theories of drawing up, drafting, provision and use of accounting information. The role of accounting is to provide accurate and transparent data about the financial position and performance of an entity, which enables managers to make the right decisions in the best interests of shareholders. For this reason, accounting information must be characterized by credibility and social validation, features that ensure the understanding and trust of users. By supporting quality financial reporting and ensuring a credible financial environment with a low degree of uncertainty, the professional accountant participates in the development of international markets and reduction of their volatility.

In our opinion, facilitating access to information, including effective communication thereof, represents "vehicles" that sets the global market in motion, stimulating investment and promoting efficient decision-making. The investment policy of an enterprise depends on the degree of understanding of the information provided by the accounting, as well as on the correctness of the other partners. Consequently, the integration of goods and services on the world market ultimately also depends on the quality of the accounting information supply.

The need to inform users requires the achievement of the accounting performance objective, namely the achievement of a true, clear and complete picture of the economic resources controlled by the company, of the financial situation and the result of the year. We can see how the professional accountant must make every effort to reflect the reality in a unitary way, as the financial auditor certifies the faithful representation of this reality. As fundamental step in the accounting profession, the financial audit must check, analyse, test and certify the results and information provided by the accounting, so that, subsequently, they can play the supporting role in decision-making. Because the number of users of financial and accounting information is very high and their needs differ greatly, it is difficult to achieve an objective assessment of their quality. However, we mention that in the case of information provided by accounting, quantity matters, but especially quality. This element is the essence of any information, not just of accounting, and is, thanks to international harmonization and convergence, in a continuous process of improvement. Practice has shown that professional judgment is responsible for ensuring the balance between the qualitative characteristics of information, so that it meets the objective of the financial statements. The quality of the information and the professional standards enable the obtainment of the faithful image, validated through the financial audit.

In our opinion, accounting information is the most important product circulating between companies and it must be able to identify, evaluate, measure and clarify all events and transactions that take place in a company. Also, most of the decisions taken by management on behalf of stakeholders are based on it. In short, the information must be of 
quality, a product of the responsible activity of the account professionals. Precisely because the information is ubiquitous and access to it is easy, its certification through financial audit has become indispensable.

Accounting harmonization has been and is a promoter of transparency in the business world but free access to information makes it difficult to distinguish between true and false. For these reasons, in all countries of the world, the financial audit appeared and developed, which took over the role of external control, independent and objective, enforced by professionals in the field who carry out their activity under the law. Through their approach, financial auditors support the users, guaranteeing through the audit report and opinion the sincerity and the faithful representation of the financial statements. The audit gives the accounting information the character of neutrality, namely the reasonable assurance that it does not favour a particular interested party. Research literature, but especially the practical life has shown us many cases, including at the highest level, of fraud and bankruptcy based on falsification of accounting data. So, here is an additional argument for the audit due to its function of external and objective control of accounting reporting.

\section{Quality criteria in the financial audit}

Following the research of the specialized literature and the practice of the field of accounting and financial audit, we believe that there is a direct connection between the independence and competence of the professional, on the one hand, and the quality of the audit mission, on the other hand. The consequences of this link are visible in relation to the users' trust, which underlie their decisions on the faithful image and accounting truth certified by audit. We are aware that the lack of competence and dysfunctional behaviours negatively influence the quality of the audit, but also the general perception of the profession. In an interesting study of the elements that may be associated with the auditor's lack of competence, with a direct effect on audit quality, McNair summarizes the following (McNair, 1991):

- reducing the working time assigned to the audit mission;

- $\quad$ acquiring the improbable and inadmissible explanations offered by management;

- brief check of the supporting documents that represented the basis of the accounting record;

- incorrect establishment and evaluation of the questions contained in a questionnaire.

The most common cause of these inappropriate behaviours of audit team members is the practice of superficial quality control within the audit firm or office. Performance evaluation methods must represents the basis for the hierarchical promotion of staff and the influence of leadership should be a decisive component for the quality of the audit. By applying a rigorous performance-oriented business model, experienced partners in the audit firm are likely to improve the quality of the activity of validating the faithful image and accounting truth contained in the financial statements. In our opinion, the improvement of these shortcomings, inherent in most audit companies, is achieved, first of all, by placing the criterion of independence at the centre of the activity. This enables the reporting in time of the errors and omissions identified by the auditor in carrying out its checks. Independence is an explanatory criterion of the quality of the audit, being in fact a mental 
state through which the auditor does not feel constrained or subordinated to the internal and external influences of the company he/she works for or pressured by possible conflicts of interest.

We emphasize that, as in the case of valuation or bookkeeping, independence nevertheless obliges the professional to respect and apply the standards, based on professional reasoning, in order to provide a certification of the quality of the mission, identifying all significant errors and omissions. In short, independence does not allow deviation from the rules. The role of independence is to test the resilience of the auditor to the pressures exerted by the environment, whether we are referring to those from the client or those exerted by superiors. The drafting and development of audit standards aims, first of all, to provide a clear picture, through the audit report, of compliance with all the rules relevant to the financial statements of a company, in conditions of independence. Their application supports the auditor, precisely because it does not have to choose between a sincere opinion and the pursuit of its own interest.

In the opinion of the author dit Hauret, independence in the audit is divided in independence of spirit and the appearance of independence, the two being cumulative conditions for achieving the quality desideratum (dit Hauret, 2003). In a similar way, Richard divides the concept of independence into independence in deeds and independence in appearance (Richard, 2006). We consider the opinion of the two authors as a valid and totally justified one, because we are in the business world, where trust is key and independence in deeds is not enough. The others' perception about a person's degree of independence is extremely important and the auditor must visibly demonstrate this. This is evidenced by the widespread trend of multinational companies to rely strictly on the services of large audit firms which, in addition to the competence and independence demonstrated in most cases, their success is largely guaranteed by the apparent independence they experience.

Independence alone cannot ensure the quality of the audit. We identified the concepts of expertise, responsibility and efficiency, as fundamental criteria that form the professional behaviour and the technical dimension of the audit activity. The latter is made up of all the knowledge specific to the field that a professional has and that is necessary for him in the successful accomplishment of his mission.

The qualities of the auditor are not limited to knowledge of auditing standards, rules and procedures. They also require a significant economic culture, information on the client's field of activity and experience in running a business. If we add the experience in the field, these types of knowledge make up the auditor's expertise, or in other words, his ability to adapt to the specifics of each company and solve complex problems, while ensuring the quality of the audit and guaranteeing the accurate image of the accounting information. in the financial statements. Professional behaviour refers to the concepts of responsibility and efficiency stated above. From the mentioned statements we deduce that responsibility is a complementary criterion to independence. Even if all the criteria are met, the auditor's independence is guaranteed only by its attitude towards its responsibilities. His approach in relation to possible conflicts of interest and the observance of professional deontology are related to the ability to assume responsibility in connection with the activity performed. Regarding the efficiency of the audit, the link between it and quality is highlighted by means of the studies carried out by Elitzur and Falk (1996) and Trombetta (2003). 


\section{Significant misstatements of the financial statements}

Discussions regarding major financial scandals or economic crises are dominated by the role of inappropriate government policies, investor greed, capital market speculation and growing deficits. Few studies focus on other related causes such as lack of a responsible organizational culture, business ethics and failure to assume liability. The values that underpin sustainable development and healthy economic growth have been forgotten, putting selfish desires and interests in a place of honour. Unfortunately, this totally incorrect attitude was also displayed by some professional accountants or auditors. Under such conditions, instead of rigorous observance of professional deontology, compromise and deliberate ignorance of the norms of ethics and morality appeared. The responsibility for preventing and detecting errors and fraud lies within the area of liability of contractors, but also of the management. In their work, financial auditors must take into account the risk of material misstatement in the financial statements as a result of errors and even fraud. Even if the auditor is responsible for the planning of the audit, the collection of evidence, compliance with norms and standards, the estimation and observance of the materiality threshold, it does not have the role of detecting all the misstatements contained in the financial statements. Moreover, it is important to note that the auditor cannot provide absolute assurance because the audit evidence is obtained by sampling and testing and cannot always be perfectly conclusive. Much of the information is based on estimates by the accounting department in relation to a number of uncertainties and fraud is difficult to disclose if management is involved in covering it. For this reason, when determining the nature, duration and scope of the audit assignment, the auditor should be professionally skeptical in relation to any statement, transaction or event of the audited entity.

Assigning a professional to carry out the financial audit does not relieve the management of the company of its responsibility in drafting and drawing up financial statements, or of internal control for preventing and detecting errors and omissions. The total elimination of the risk of fraud remains a goal, an ideal unattainable until now. The role of internal audit and control systems at the level of a company is to reduce to an acceptable level the possibility of fraud, but we must not ignore the repetitive nature of small errors that can result into massive fraud.

From our point of view, studying the subject from an accounting perspective, it is worth noting that the main elements involved in detecting fraud and other components that adversely affect the faithful image and accounting truth are: internal control, internal audit and risk management. As a result of studies carried out by audit and consulting firms, the business community can more easily understand the effects of fraud on the business world, may develop improved risk assessment models and look for additional methods to prevent crime. By performing a deeper analysis of the causes of these adverse events in the economy, we identify, almost every time, the failure of professional accountants or auditors to assume responsibility. If the actors involved had carried out their activity responsibly, in accordance with ethics and deontology, many of these would not have taken place.

The carrying out of economic activity has always had as its objective the achievement of profit, a basic condition that has demonstrated its social utility. All the peculiarities of economic life are organized and managed by the human factor whose aim, in many cases, is that of obtaining gains and benefits, in any form and by any method. This is where the need to regulate by means of law, norms and standards of any human activity 
comes from, while the check of compliance with those in the economic area is the responsibility of the financial audit. As long as economic and accounting science considers the faithful image reflected by the financial statements as the most important element and consider it a basic condition for the smooth running of the economy, the role of financial audit as a function of validating accounting truth is adamant.

It is important to note that behind the audit report and opinion lies a complex activity of a highly trained professional body, assisted by experts who come to cover those areas that intersect with the audit and that the auditor does not know in depth. In our opinion, the work of the auditor is a filter that is interposed between the producers of accounting information and its users. The latter consider the audit report as a "warranty certificate" issued for the audited financial statements and the assurance that they represent a faithful and fair view of the economic and financial activity of the company.

We must also consider the observance of the Codes of Ethics and of the profession deontology, which is, first of all, a moral obligation for any practitioner. When it comes to accounting practitioners, be they accountants or auditors, liability is a fundamental and mandatory principle as they operate in a sector that has the power to influence the general state of the economy. Integrity cannot be imposed through documents, but can be promoted and acquired through a healthy educational culture and maintained through rigorous professional training.

\section{Challenges for accountants and auditors}

The mission of the professionals in the field of accounting is to operate and function in the public interest, namely of the society as a whole, because all social actors are, either directly or indirectly, affected by the accounting activity. The public places their trust and capital in the hands of a management that they consider honest and efficient and to ensure this, they turn to accountants and auditors. Accounting has undoubtedly brought a certain rigor and discipline to economic life, promoting confidence in the business world. But challenges exist at all times and the subject of accounting must prove ability to adapt to the ever-increasing and diverse requirements. At all times, financial decisions are made based on the relevance and objectivity of the information presented by the accounting and for this reason, the criterion of faithful image is of utmost importance, both for information producers (accountants) and for those who validate it (auditors). Ensuring the production and certification of a faithful image becomes a challenge for professionals due to fiscal, legal or customary changes. In the work of auditors and accountants, the quality of services provided is paramount. The qualitative characteristics of information are the product of personal judgment, influenced by a combination of factors. We take into account the studies carried out, the professional training and the qualification, up to the work experience, the availability of continuous documentation and the degree of freedom in decision making. The shortcomings found in keeping or auditing the accounts are, most of the time, deficiencies of professional reasoning, manifested by insufficient knowledge, low level of training or lack of experience.

Both accounting and financial auditing must respond to the constant changes in the economic landscape and support the business environment in order to adapt to them. One of the challenges is taxation, as repeated legislative changes create fiscal instability, 
generated by the need to harmonize with European legislation and by the lack of long-term strategies (Holt and Hein, 2001).

Another challenge for the accounting profession is the ability of information to keep its relevance over time. Research literature shows the opinion of some institutions and practitioners who consider that in the current economic context, given the increasingly complex operations and the current financial reporting system considered unsustainable, the information loses its relevance. Relevance is also threatened if there is a delay in reporting information. Even if it maintains its credibility, it is of little use to users as it is possible that they have already made economic decisions before they have all the data at their disposal. That is why it is essential to have a balance between relevance and credibility that supports the decision-making process. The activity of today's professional accountant is not limited to the chronological recording of financial operations, as he must show that he has a critical, analytical thinking, must show logic, education, planning and have an ethical attitude. Thus, the knowledge acquired during academic studies alone is sufficient and he must participate in vocational training programmes, be aware of legislative changes and know the standards so that his abilities are acknowledged. The learning process is life-long, so that he may have the qualities necessary to carry out a quality accounting activity. The financial auditor faces the same challenges.

Another challenge is represented by the shift of entities to IFRS reporting, which involves a number of specific risks arising from differences in both reporting manner and company size, the complexity of operations or the effect the reporting framework change on accounting. Maintaining independence is a major challenge, especially for financial auditors. The financial scandals of the last two decades have affected the reputation of the profession, in some cases the integrity of auditors being called into question when they offered favourable audit opinions to companies that soon went bankrupt. That is why, as we have pointed out before, maintaining trust is paramount for the audit activity and this can only be achieved by maintaining independence.

The possibility for the financial auditor not to identify all errors in the financial statements, regardless of the rigor of checks, of obtaining audit evidence and applying standards is specific to the audit activity. For this reason, the beneficiary of the report should be aware that the auditor cannot provide absolute assurance, as there are inherent limitations (especially in the case of internal control) that affect the ability of the audit to recognize all significant misstatements.

\section{Conclusions}

Accounting is the product of the evolution of economic practice over time. The improvement of economic conditions and the enhancement of the business activity are based on the most advanced knowledge possible of the events and phenomena governing processes of this type, quantified and recorded in accounting language. The concept of performance of accounting information is given by the faithful image and the extent to which it manages to present an objective, accurate and complete reality of economic facts, as well as by the degree of validation of accounting truth achieved through auditing.

We conclude that in the current economic and political context, the need to validate the financial information provided to users but also the quality of accounting activity and audit missions has gained a prominent place. The drawing up and dissemination of 
information by a company is an act of will, a product of human reasoning, namely a social phenomenon. Thus, this activity must be characterized by quality information, obtained from a responsible approach, by ensuring a high level of transparency.

\section{References}

1. Elitzur, R., \& Falk, H. (1996). Planned audit quality. Journal of Accounting and Public policy, 15(3), 247-269. https://doi.org/10.1016/0278-4254(96)00024-5

2. dit Hauret, C. P. (2003). Audit et développement moral cognitif. Revue Finance Contrôle Stratégie, 6(3), 117-136.

3. Holt, P., Hein, CD (2001) International Accounting, 5th edition, Dame Thomson\&Learning, Cincinnati

4. Ionaşcu, M., \& Ionaşcu, I. (2012). The use of accounting information by financial analysts in emergent markets: the case of Romania. Journal of Accounting and Management Information Systems, 11(2), 174-186.

5. Ionașcu, M., Ionașcu, I., Săcărin, M., \& Minu, M. (2017). Exploring the impact of ISO 9001, ISO 14001 and OHSAS 18001 certification on financial performance: The case of companies listed on the Bucharest Stock Exchange. Amfiteatru Economic Journal, 19(44), 166-180.

6. McNair, C. J. (1991). Proper compromises: The management control dilemma in public accounting and its impact on auditor behavior. Accounting, Organizations and Society, 16(7), 635-653. https://doi.org/10.1016/0361-3682(91)90017-9

7. Prat Dit Hauret, C. (2003). L'indépendance du commissaire aux comptes: une analyse empirique fondée sur trois composantes psychologique du comportement. Comptabilité contrôle audit, 9(2).

8. Trombetta, M. (2003). International regulation of audit quality: full harmonization or mutual recognition? An economic approach. European Accounting Review, 12(1), 3-27. https://doi.org/10.1080/0963818022000001073

This article is an open access article distributed under the terms and conditions of the ommons Attribution - Non Commercial - No Derivatives 4.0 International License. 